\title{
Escenas decibles, escenas indecibles: raza y sexualidad en Gilberto Freyre
}

\author{
Speakable scenes, unspeakable scenes: race and sexuality in Gilberto Freyre \\ Cenas dizíveis, cenas indizíveis: raça e sexualidade em Gilberto Freyre
}

\section{Idelber Avelar}

TULANE UNIVERSITY, ESTADOS UNIDOS

Profesor en el Departamento de Español y Portugués en la Universidad de Tulane; PhD por la Universidad de Duke. Escribe sobre ficción, teoría-crítica y estudios culturales en Latinoamérica. Entre sus libros, destacan: Transculturación en suspenso: Los orígenes de los cánones narrativos colombianos (Instituto Caro y Cuervo, 2015), Crônicas do estado de exceção (Azougue, 2015), Figuras da Violência: Ensaios sobre Ética, Narrativa e Música Popular (UFMG, 2011) y The Untimely Present: Postdictatorial Latin American Fiction and the Task of Mourning (Duke UP, 1999). También es coeditor de Brazilian Popular Music and Citizenship (Duke UP, 2011). Correo electrónico: iavelar@tulane.edu

Agradezco al American Council of Learned Societies (ACLS) por la beca que me dio la posibilidad de dedicar un año sabático a la investigación sobre masculinidades. Una versión en portugués de este texto fue publicada en Luso-Brazilian Review 49.1 (2012). Su traducción al español es de Cristián Opazo.

Documento accesible en línea desde la siguiente dirección: http://revistas.javeriana.edu.co 


\section{Resumen}

Este artículo aborda la intersección entre raza y sexualidad en Casa-grande e senzala y Sobrados e mucambos de Gilberto Freyre. Tras una introducción que delinea cómo la sexualidad permea todo el cuerpo político en estos trabajos, procedo a mostrar la naturaleza fluida y porosa de la frontera entre homo y heterosexualidad en la escritura de Freyre.

Enseguida, paso a la discusión de la asimetría de representación de las relaciones sexuales interraciales en Freyre. Concluyo sugiriendo que ese escenario indecible ofrece una entrada al inconsciente de la trilogía de Freyre sobre el Brasil patriarcal.

Palabras clave: raza; sexualidad; masculinidad; ensayismo brasileño; Gilberto Freyre

\section{Abstract}

This article addresses the intersection between race and sexuality in Casa-grande e senzala y Sobrados e mucambos by Gilberto Freyre. After an introduction describing how sexuality permeates the entire political body in these works, I proceed to show the fluid and porous nature of the boundary between homo and heterosexuality in Freyre's writing. Afterwards, I turn to the discussion on the representation asymmetry of interracial sexual relations in Freyre. I conclude by suggesting that this unspeakable scenario offers an entrance into the unconscious of Freyre's trilogy on patriarchal Brazil.

Keywords: race; sexuality; masculinity; Brazilian essayism; Gilberto Freyre

\section{Resumo}

Este artigo aborda a interseção entre raça e sexualidade em Casa-grande e senzala e Sobrados e mucambos de Gilberto Freyre. Após uma introdução que delineia como a sexualidade permeia todo o corpo político naqueles trabalhos, procedo a mostrar a natureza fluída e porosa da fronteira entre homo e heterossexualidade na escrita de Freyre. Seguidamente, passo à discussão da assimetria de representação das relações sexuais inter-raciais em Freyre. Concluo sugerindo que esse cenário indizível oferece uma entrada ao inconsciente da trilogia de Freyre sobre o Brasil patriarcal.

\section{Palavras-chave: raça;} sexualidade; masculinidade; ensaísmo brasileiro; Gilberto Freyre

RECIBIDO: 15 DE JULIO DE 2016. ACEPTADO: 01 DE DICIEMBRE DE 2016. DISPONIBLE EN LÍNEA: 29 DE DICIEMBRE DE 2017

\section{Cómo citar este artículo:}

Avelar, Idelber. "Escenas decibles, escenas indecibles: raza y sexualidad en Gilberto Freyre".

Cuadernos de Literatura 21.42 (2017): 96-118. https://doi.org/10.11144/Javeriana.cl21-42.edei 


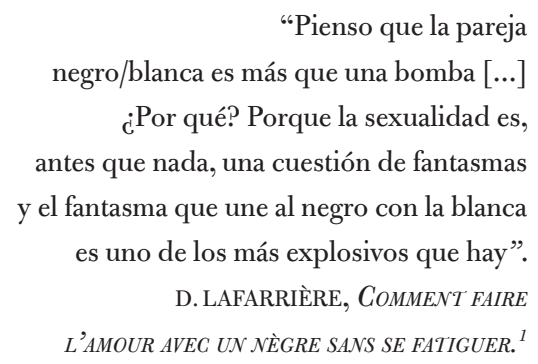

En cierto sentido, Mara Viveros Vigoya está en lo correcto al decir que sólo al final de los años 80 comenzaron en América Latina las investigaciones que describen al hombre como poseedor y productor de género. Hasta entonces, los hombres eran identificados como humanos en general, y el privilegio masculino se tornaba o invisible o problema exclusivamente del hombre (27).

Es verdad que hay una larga tradición de naturalización del privilegio masculino que se sustenta en la premisa del hombre como sujeto universal. Es correcto afirmar que tal naturalización, con frecuencia, ha hecho del problema del hombre como sujeto poseedor de género una cuestión invisible o imposible de ser expuesta. Y también es cierto que la práctica y la teoría feministas son directamente responsables de la posibilidad de relevar, de manera sistemática, preguntas sobre la masculinidad. No obstante, basta una breve mirada a las tradiciones intelectuales de, por ejemplo, Brasil o Cuba, para confirmar que el pensamiento canónico en América Latina ha tratado, repetidamente, al hombre como poseedor y productor de género - si bien, no en el sentido en que lo hacen los estudios contemporáneos de la masculinidad-, pero sin ignorar del todo la cuestión masculina universalista, siempre ciega a la especificidad del género.

En Brasil, el caso más elocuente es Gilberto Freyre y su trilogía Introducción a la sociedad patriarcal en Brasil (Casa-grande e senzala, Sobrados e mucambos y Orden e progresso). Un libro como Casa-grande e senzala (1933) sería simplemente ilegible bajo el presupuesto de que, antes de los años 80, el pensamiento latinoamericano no describía al hombre como "poseedor y productor de género". Ese, el más ilustre de los textos de ensayo brasileño sobre identidad nacional, no es sino un estudio del hombre como poseedor y

1 Salvo que se indique lo contrario, todas las citas que no se presenten en su lengua original, han sido traducidas (nota del editor). 
productor de género. La verdad es que podríamos definirlo como un ensayo acerca de la sobreproducción de género, sobre la extensión del problema de género a la totalidad de la polis.

Casa-grande e senzala ha traducido la versión canónica de la autocomprensión nacional, en parte, por la posición central que el libro le confirió a la sexualidad. Freyre representó tanto la crítica definitiva y la superación de la antropología racista, como el papel sospechoso de haber suavizado y endulzado el racismo estructural brasileño. Gran parte de la tradición crítica de esta elusiva figura se dedica a escoger uno de estos polos o a optar por una oscilación entre ellos, y así replicar la estrategia retórica preferida por los textos del propio Freyre. Tal vez eso sea inevitable. En todo caso, Freyre, reconocido unánimemente como cofundador de las ciencias sociales modernas brasileñas - al lado de Sérgio Buarque de Hollanda, Caio Prado Jr. y otros integrantes de la escuela paulista-, ocupa una posición única. Ha escrito en un lenguaje más literario que sus contemporáneos, ofrece un texto que procede según una lógica que podríamos llamar poética, y su versión de la realidad brasileña produjo una forma de coherencia narrativa, más que estricta o meramente científica. Como sucede, por ejemplo, con Friedrich Nietzsche, el texto de Freyre incluye varios fragmentos que sustentan lecturas antagónicas. Como percibió Luiz Costa Lima, Freyre "suspende la desconfianza fundamental que el pensamiento occidental nos enseñó a mantener con respecto a la contradicción" (227). En su crítica a las aproximaciones estadounidenses sobre Freyre - lecturas que lo plantean como el promotor de un paraíso racial en los trópicos-. Hermano Vianna también apuntó que no hay nada más fácil que reunir dos conjuntos de citas freyreanas mutuamente contradictorias (201).

A riesgo de simplificar una tradición crítica bastante compleja, podríamos identificar cuatro grandes tendencias sobre la recepción de la obra de Freyre. Naturalmente, hay también una intersección significativa entre ellas.

[1] Tras la publicación de Casa-grande e senzala hubo un impacto inicial notable, descrito por Antonio Candido como un "terremoto" (citado en Pontes 7). Freyre consolidaba su nombre como el antropólogo que trascendía las interpretaciones racistas y biologistas de Brasil, en cuanto país de un mestizaje que debía ser corregido o sufrido como fatalidad irredimible, mestizaje que siempre había sido tomado negativamente. Con ese efecto inmediato, que se extiende a lo largo de los años, Freyre aparecía como el discípulo innovador de Franz Boas, quien validaba antropológicamente las contribuciones africanas al Brasil y ofrecía una respuesta categórica a la antropología 
pseudocientífica de las razas inferiores. Ya en su impactante comienzo, Freyre combinaba la erudición de un investigador que estaba, por un lado, al día en las últimas bibliografías científico-sociales de su tiempo y, simultáneamente, equipado para hacer uso de la tradición intelectual, de los archivos históricos y de la experiencia cotidiana del país. La lectura inicial de Freyre tuvo un tono de marcado elogio, aunque algunas reseñas incluyeran ciertas observaciones críticas como, por ejemplo, que la obra de Freyre no se ocupaba realmente de la totalidad de Brasil, como él afirmaba, sino que era válida solo para el Noreste, o que su lenguaje era por demás vulgar o contaminado de oralidad (Giucci y Larreta 932-933). Las mejores guías de aquel momento de recepción de Freyre continúan siendo Casa-grande e senzala e a crítica brasileira de 1933 a 1944 (organizado por Edson Nery de Fonseca), que compila las primeras reseñas, y Gilberto Freyre: Sua ciência, sua filosofia, sua arte (editado por Gilbert Amado), volumen conmemorativo del $25^{\circ}$ aniversario de la publicación de Casa-grade e senzala, que presentaba a Freyre como fuerza de renovación en las ciencias sociales e incluía artículos de figuras de punta en las letras brasileñas como los críticos Antonio Candido, Otto Maria Carpeaux y Lúcia Miguel Pereira (esta última conocida por sus estudios sobre Machado de Assis); escritores canónicos como Jorge Amado, Osman Lins, Carlos Drummond de Andrade, Manuel Bandeira y Ariano Suassuna; el abogado Miguel Reale y hasta el precursor comunista Astrojildo Pereira. No fue sin razón que una de las palabras más recurrentes en los títulos del volumen conmemorativo fuera "valorización" (con ensayos que aludían a la valorización freyreana, por ejemplo, de la mujer, del negro y del portugués). Una serie de artículos sobre temas que iban desde la medicina hasta la arquitectura contribuían a una presentación de la obra de Freyre como un relato totalizador de la cultura brasileña, capaz de dialogar con varias disciplinas.

[2] De forma casi simultánea, surge también una provechosa tradición interpretativa que hace de Freyre objeto de crítica, inspirada, en mayor o menor grado, en la tradición marxista de la Universidad de San Pablo. Florestan Fernandes, Caio Prado Jr., Fernando Henrique Cardoso, Antonio Candido y otros presentarían, en diferentes momentos de sus trayectorias, críticas incisivas a Freyre por su vindicación voluptuosa de un orden social brasileño del que la violencia de la colonización había sido, por lo menos parcialmente, tachado. Coincidentemente, 1933 , año de la publicación de Casa-grande e senzala, también vio la publicación de la primera gran obra de interpretación marxista de la historia brasileña, la Evoluçâo política do Brasil, de Caio Prado Jr. Como notaría Carlos Guilherme Mota (Ideologia), tal vez el prin- 
cipal cronista de aquellos debates, el pensamiento sociológico de izquierda criticaría a Freyre por su supuesto culturalismo, su desconsideración de la ley de determinación económica y su abordaje de la cuestión racial fuera del marco de la lucha de clases. Para el pensamiento sociologizante que surgía en San Pablo en aquel momento, el culturalismo de Freyre llevaba, como diría Antonio Candido, a "disfrutar del dulce de guayaba de las tías y [de] una democracia patriarcal" (citado en Mota, "Universidade" 173). Sin dejar de reconocer Casa-grande e senzala como una obra maestra de realización narrativa y literaria, el pensamiento sociológico brasileño influido por el marxismo se puso en frontal oposición al texto. Más allá de las diferencias políticas, la fisura entre Freyre y la escuela de la Universidad de San Pablo también se remite a una batalla metodológica acerca de lo que debería contar como sociología genuinamente científica en Brasil. Buena parte de la crítica lanzada a Freyre por sus rivales de San Pablo tenía con ver con su supuesta falta de rigor y con la naturaleza ensayística de su escrito. Irónicamente, Florestan Fernandes, tal vez el miembro más ilustre de la escuela paulista, admitió - como es sabido- que las evidencias científicas y el método experimental no eran suficientes para determinar, de una vez por todas, quién tenía la razón en el debate. También hubo momentos de breve aproximación entre Freyre y la escuela paulista, como en la visita de Fernandes a Recife, en 1961, seguida por la invitación a que Freyre recibiese un homenaje en San Pablo, durante el cual participaría de la mesa de doctorado de Fernando Henrique Cardoso y Octavio Ianni -invitación que Freyre rechazó-. El abismo entre ambos solo se ampliaría con los años en la medida en que Freyre asumía posiciones más reaccionarias, en defensa del golpe militar brasileño de 1964 y del colonialismo portugués en África. En el vasto campo de pensamiento progresista y de la izquierda, solo Darcy Ribeiro se permitió ser seducido por la prosa de Freyre y ofreció defensas apasionadas del pernambucano. Es significativo, como apunta Joaquim Falcão (148), que Darcy Ribeiro no fuese de San Pablo y que su elogio principal haya sido parte de una publicación extranjera: el prólogo a la traducción al español de Casa-grande e senzala para la Biblioteca Ayacucho, en Venezuela.

[3] De forma independiente a esas dos tendencias brasileñas, floreció también una larga historia de recepción estadounidense de la obra de Freyre, a veces en diálogo con la equívoca historia del término democracia racial, atribuido a Freyre, aunque ausente de sus obras fundamentales y no utilizado por él, por lo menos por escrito, hasta 1962. La historia es compleja, ya que Freyre fue, en gran medida, cómplice de esa lectura parcial de sus textos. 
El término democracia racial parece haber sido utilizado por primera vez por Arthur Ramos en 1943. Fue tomado después por el sociólogo francés Roger Bastide, en contextos en los que hacía alusiones a la obra de Freyre. Tal vez todavía sorprenda a algunos el hecho de que, antes de ser largamente criticado en los Estados Unidos, como una ilusión de la cual los brasileños supuestamente habrían caído presa, el término era moneda corriente en el propio movimiento negro, en un contexto de relativa cooptación del movimiento para el proyecto de una identidad nacional sin fracturas. Esto se puede notar en el discurso de Abdias do Nascimento en el Primer Congreso de Negros Brasileños, lleno de referencias a la "bien definida doctrina de la democracia racial" que ofrecería una "lección y un modelo a otros pueblos con formaciones étnicas complejas como la nuestra (citado en Guimarães, Classes 144). No es la menor de las ironías en esta equívoca historia que el principal líder del movimiento negro brasileño haya usado la expresión "democracia racial" mucho antes que el ensayista que supuestamente habría creado el mito responsable de la invisibilización de los reclamos afrobrasileños. La expresión fue moneda corriente en el movimiento negro durante los años 50 y, entre 1948 y 1950, el periódico Quilombo, editado por el propio Abdias do Nascimento, "publicó una columna titulada precisamente 'Democracia racial"" (Guimarães, "Racial" 12), con artículos de intelectuales comprometidos con la causa antirracista, incluidos Freyre, Bastides y el poeta Murilo Mendes. Dentro de la institucionalización de las interpretaciones anglófonas de Freyre, un momento importante fue la conclusión de Charles Wagley para el proyecto de estudio de las relaciones raciales brasileñas, patrocinado por la UNESCO, en 1952, en la que Wagley defendía la hipótesis de la existencia de un prejuicio racial "suave" en el país. En 1959, la propia elección de Freyre para el título de una de sus publicaciones en los Estados Unidos no podría haber sido más reveladora: New World in the Tropics. La bibliografía en lengua inglesa sobre Freyre va desde la exaltación de una supuesta democracia racial a una crítica al supuesto abrazo de Freyre a ella como una realidad efectivamente existente. El prefacio de David H. P. Maybury-Lewis a la edición empastada de la traducción de Casa-grande e senzala al inglés fue uno de los marcos de esta crítica: su admiración por el libro no le impidió atacar a Freyre por no ajustar cuentas con el racismo portugués, por endulzar la experiencia de la esclavitud y por presentar una imagen engañosamente armónica de las relaciones raciales brasileñas. Se podrían mencionar libros como el de Stuart Schwartz, Sugar Plantations in the Formation of Brazilian Society, escrito como respuesta a la versión "dulce" de Freyre sobre la escla- 
vitud y para presentar al pernambucano como autor de una interpretación "feudal" de la sociedad brasileña (Schwartz 254). Esta bibliografía devela la injusticia estructural, la opresión y el racismo brasileños de forma valiosa, pero también difunde hasta el presente la noción errónea de que "el concepto de 'democracia racial' fue desarrollado por el ensayo canónico de Freyre en 1933, Casa-grande e senzala" (Arroyo 58), como si esa expresión existiese en algún lugar del libro. En todo caso, una buena parte de la bibliografía estadounidense sobre Freyre demostraba una ansiedad considerable acerca de la propia configuración racial de los Estados Unidos, ansiedad sublimada a través de una crítica de las relaciones raciales brasileñas.

[4] Más recientemente, una vuelta a la obra de Freyre (Dunn 35-51) ocupó a una serie de ensayistas y científicos sociales brasileños, desde Ricardo Benzaquen de Araújo a Hermano Vianna y Antonoi Riséiro. Particularmente, los dos últimos son bastantes críticos de lo que consideran una importación de las visiones raciales binarias de los Estados Unidos. Los neofreyreanos han insistido en la disociación entre (a) la valoración positiva del mestizaje - elemento que ellos continúan reivindicando - y (b) la suposición de un paraíso racial efectivamente existente. Mientras que la bibliografía estadounidense, con frecuencia, presenta una crítica del (supuesto) mito de la democracia racial, la escuela neofreyreana ha apuntado, con perspicacia, la existencia de un "mito del mito de la democracia racial", o sea, una percepción idealizada del poder real de la supuesta creencia brasileña en la armonía de sus relaciones raciales. Como observa Hermano Vianna, el mito del mito de la democracia racial presupone que "en algún lugar del pasado hubo locos que escribieron tal barbaridad" (255). En este retorno a Freyre, la interpretación más aguda fue la de Ricardo Benzaquen de Araújo, en su Casa-grande e senzala e a obra de Gilberto Freyre nos anos 30, en la que reconstruye un diálogo de la obra con el modernismo y analiza el "equilibrio de antagonismos" como su estrategia retórica central. De cierta forma, Benzaquen de Araújo elude las posiciones más polarizadas del debate precisamente porque se mimetiza con las estrategias retóricas del propio texto de Freyre: hace uso de la paradoja, el oxímoron, la oscilación entre términos antagónicos. ${ }^{2}$ Otro marco de esta vuelta a Freyre es la colección de ensayos $O$ imperador das ideias, publicada

2 Como muestra Alfredo César Melo en un perceptivo artículo, el conservador Freyre lee con mayor propiedad la coexistencia de temporalidades en la sociedad brasileña que los propios sociólogos uspianos, confiados en la eventual superación del atraso por el progreso. Véase el notable contraste entre Freyre y Sergio Buarque de Hollanda presentado por Melo. 
para el $100^{\circ}$ aniversario del nacimiento de Freyre, en la que por lo menos tres artículos (el de João Cezar de Castro Rocha, el de Carlos Guilherme Mota y el de Joaquim Falcão) analizan exactamente la fragmentación ya mencionada entre Freyre y la escuela paulista. Como se hace patente en Gilberto Freyre e os estudos latino-americanos, libro coordinado por Joshua Lund y Malcolm $\mathrm{McNee}$, un elemento recurrente en la nueva bibliografía es la separación entre la discusión del mestizaje y cualquier ilusión acerca de una armonía racial. En otras palabras, la reivindicación del mestizaje como visión deseable para el país no implica necesariamente suscribir todos aquellos pasajes de Freyre -indudablemente presentes en su obra, aunque contradichos por otrosque ofrecen una versión endulzada de las relaciones raciales brasileñas.

Desde el inicio de esta historia hasta sus momentos más próximos, la sexualidad ha estado en el centro de la discusión. La sexualidad es, en Freyre, "instrumento de poder en el ámbito de la familia patriarcal" y, al mismo tiempo, "territorio de negociaciones y amortiguación de contradicciones en el seno de la esclavitud y de las jerarquías coloniales" (Vainfas 781). No solo el análisis que hizo Freyre de la estructura social brasileña está atravesado por referencias a cuestiones de género y sexualidad. El propio lenguaje que se observa en su trilogía es entendido, desde muy temprano, a partir de una lógica sexualizada. En su introducción a la segunda edición de Sobrados e mucambos, Freyre mencionó algunas de las críticas recibidas por Casa-grande e senzala, entre ellas la de que se había basado en una sociología no muy viril o masculina (802-803). La tensión entre Freyre y las corrientes cuantitativas y supuestamente más científicas de la sociología y la antropología fue, entonces, codificada en términos de género desde el inicio de las lecturas de su obra, en la medida en que se estableció una lectura de Casa-grande e senzala como libro con preocupaciones femeninas, excesivamente apegado a la esfera doméstica de la vida cotidiana. De acuerdo con aquella sociología "viril", la obra de Freyre no les hacía justicia a las esferas política y jurídica masculinas. Dentro del típico patrón freyreano de equilibrio de antagonismos, su respuesta a esta crítica es seguida inmediatamente por una consideración del reclamo opuesto: el de que él no prestó suficiente atención a una supuesta sobrevivencia de un (supuesto) matriarcado africano en Brasil. En una palabra, sería difícil encontrar, en torno a la trilogía de Freyre, una polémica en la cual el género y la sexualidad no estuviesen en el centro del debate.

En los relatos de Freyre sobre demostraciones no sancionadas de sexualidad, como las aventuras de mujeres casadas, el principio de equilibrio de antagonismos da lugar al oxímoron, al choque entre afirmaciones antagóni- 
cas. Mucho más que en el caso de las experiencias homosexuales masculinas, que aparecen relativamente libres de censura en Casa-grande e senzala, el típico párrafo freyreano sobre las escapadas de mujeres casadas incluye un verdadero vaivén de afirmaciones y negaciones:

Nas histórias galantes contadas por Pyrard e Coreal, quem aparece auxiliando as senhoras brancas nas suas aventuras de amor são escravas negras. O mais provável é que fossem negras as principais alcoviteiras. Tudo, porém, nos leva a crer na extrema dificuldade das aventuras de amor das mulheres coloniais, a toda hora cercadas de olhos indiscretos. Olhos de frades. Olhos de negros. Olhos de sogras. (425)

Lo que es más "probable" está en clara contradicción con aquello en que "todo nos induce a creer". La probabilidad y la creencia, con frecuencia, entran en guerra en las páginas de Freyre cuando se trata de la sexualidad femenina que se expresa en formas no sancionadas por la sociedad patriarcal. Esta oscilación, presente en toda Casa-grande e senzala, reaparece en Sobrados e mucambos: "nas anedotas sobre maridos enganados - alias, relativamente raros nos dias mais ortodoxamente patriarcais do Brasil- a figura do padre donjuan foi sendo substituida pela do medico" (912). De nuevo, la anécdota es evocada en el texto solo para luego ser declarada como rara. Freyre escribe páginas elocuentes sobre la pesadilla que era la vida de la mujer más vieja que se mantenía soltera dentro del orden patriarcal, caracterizándola como "a grande vítima do patriarcalismo em declínio", siempre "em situacão toda artificial para regalo e conveniencia do homem" (915). También aquí la oscilación aparece. Luego de citar un testimonio de un viajero alemán, según el cual muchos brasileños internaban a sus mujeres para mantener una amante en casa, Freyre relativiza: "[n] os tempos coloniais parece que nao eram tao faceis nas areas de populacao mais estavel esses internamentos" (917). Ciertamente es un tributo al texto de Freyre que él haga esas contradicciones tan visibles, tanto así, que su tema pasa a ser la incongruencia misma. La hipótesis de este estudio es que las paradojas de Freyre acerca de la sexualidad expresan un conflicto entre intersecciones decibles e indecibles de raza y género, como se verá abajo.

La prosa de Freyre está a gusto con las manifestaciones de sexualidad que, en otros contextos, aparecerían como prohibidas y transgresoras. Las actividades sexuales de los miembros de la iglesia, por ejemplo, son descritas abiertamente: 
No século XVI, com exceção dos jesuítas - donzelões intransigentes- padres e frades de ordens mais relassas em grande número se amancebaram com índias e negras [...] Por trás dos nomes mais seráficos deste mundo -Amor Divino, Assunção, Monte Carmelo, Imaculada Conceição, Rosário- dizem-nos certos cronistas que em vez de ascetas angustiados pelo voto de virgindade, floresceram garanhões formidáveis. (443)

Cuando se trata de eclesiásticos libertinos, Freyre no puede ser acusado de subestimar la orgía. Casa-grande e senzala está repleto de relatos de avemarías rezados por la "mujer del obispo que está dando a luz", de historias de relaciones sexuales de eclesiásticos con esclavas en "proporciones formidables", de alusiones a actos licenciosos u obscenidades en los conventos y hasta de frailes y sacerdotes que mantenían relaciones con prostitutas. Freyre incluso presenta la "actividad patriarcal de los curas" como elemento positivo en la formación social del país, en la medida en que posibilitaba que sus descendientes tuviesen un acceso más fácil a la cultura y a la riqueza. Hay de hecho un chiste en el texto de Freyre cuando explica cómo la falta de escrúpulos de la sociedad brasileña con respecto a estas transgresiones creó un clima que hizo posible el dicho popular "mais feliz que filho de padre".

Freyre traduce la nación de forma aparentemente natural al captar dos escenas fundacionales, ambas sexuales, ambas presumidas heterosexuales, pero ciertamente también veladas por la homosexualidad. Hay una escena decible que Freyre presenta como difundida alrededor de los territorios portugueses en América: un conjunto de prácticas sexuales que van del estupro a las relaciones ilusoriamente consensuadas entre el hombre blanco y la mujer negra (y, en menor medida, amerindia). Esta escena aparece en varias partes, desde el contacto del "señorito"3 con la mamá o la madre de leche en la casagrande, hasta la pesadilla del estupro y de la violencia sexual sufridos por mujeres negras a manos de los señores de esclavos. El objetivo de este estudio no es entrar en la interminable discusión acerca de cuán realista o cuán endulzado es el retrato presentado por Freyre sobre este violento mestizaje. Se podría presentar un enorme conjunto de citas para enfatizar cualquiera de los dos lados del debate: es verdad que Freyre vio el patrón colonizador portugués como singularmente maleable gracias a la naturaleza ya mezclada, mestiza, y al historial "sensual" traído por los portugueses. Pero también es 
verdad que algunas de sus descripciones de los horrores de la esclavitud se cuentan entre las más elocuentes de su lengua.

El momento fundacional del país, siguiendo esta obra, es un acto sexual impuesto por el hombre. Esa violencia coexiste, en Freyre, con el maternalismo, o sea, el papel central de la madre en un contexto marcado, con frecuencia, por la ausencia del padre. El maternalismo, tal como dijo el mismo Freyre, no está en contradicción con el subtítulo de la trilogía: "Itrodução à sociedade patriarcal no Brasil". Freyre veía una sobrevivencia africana en Brasil, según la cual el poder era "casi siempre patriarcal, aun cuando era ejercido por una mujer: mujer-hombre, o mujer sustituta de hombre" (Freyre "Maternalismo"). Se trata, por lo tanto, de una escena compleja, un compuesto de brutalidad y suavidad en el cual la mujer de la clase dominante figura como opresora y oprimida, además de ser también - por su condición doble - una mediadora, un filtro, una apaciguadora de las relaciones de opresión en las que está inserta.

Esta escena está habitada por la homosexualidad en la medida en que la narración también incluye, para el joven blanco, la presencia subordinada de un compañero de juegos negro, imagen descrita por Freyre, nuevamente, con una mezcla entre pasajes lúdicos y un detenimiento en la violencia:

Ao muleque companheiro de brinquedo e seu leva-pancadas, já nos referimos em capítulo anterior. Suas funções foram as de prestadio mané-gostoso, manejado à vontade por nhonhô; apertado, maltratado e judiado como se fosse todo pó de serra por dentro; de pó de serra e de pano como os judas de sábado de aleluia, e não de carne como os meninos brancos. "Logo que a criança deixa o berço", escreve Koster [... " dão-lhe um escravo do seu sexo e de sua idade, pouco mais ou menos, por camarada, ou antes, para seus brinquedos. Crescem juntos e o escravo torna-se um objeto sobre o qual o menino exerce seus caprichos" [...] Lembra-nos Júlio Belo o melhor brinquedo dos meninos de engenho de outrora: montar a cavalo em carneiros; mas na falta de carneiros, muleques. (336)

Se trata aquí de uno de esos fragmentos enloquecidamente contradictorios y escurridizos de Freyre, en el que se podría encontrar elementos tanto para decir que denuncia una práctica violenta como para argumentar que presenta una versión suavizada de ella. Freyre habla, es verdad, de las repercusiones psíquicas de tales experiencias, que podrían llevar a "tendencias sádicas y masoquistas". Curiosamente, él atribuyó una presencia más aguda de esas tendencias a las mujeres por la "mayor constancia y monotonía en las 
relaciones de la señora con la esclava" (337). Freyre pasa entonces a relatar los horrores de los relatos de celos de las señoras que arrancaban los ojos a las esclavas de las que sospechaban amoríos con sus maridos. En el proceso, pasa de nuevo a segundo plano la escena homosocial entre el joven esclavo y el señorito. A pesar de que la escena heterosexual normalmente recupera centralidad, las prácticas gays aparecen documentadas en Freyre, especialmente en los relatos sobre la persecución de la sodomía en los tiempos coloniales, cuando la homosexualidad todavía no era una categoría.

El juego entre el muleque y el señorito alrededor de la casa-grande y de la habitación de los esclavos negros es la única irrupción homoerótica en la escena principal. Esta irrupción también aparece en la relación entre la "señorita" ["sinhazinha"] y su esclava doméstica:

Sabe-se que enorme prestígio alcançaram as mucamas na vida sentimental das sinhazinhas. Pela negra ou mulata de estimação é que a menina se iniciava nos mistérios do amor [...]

Histórias de casamento, de namoros, ou outras, menos românticas, mas igualmente sedutoras, eram as mucamas que contavam às sinhazinhas nos doces vagares dos dias de calor, a menina sentada, à mourisca, na esteira de pipiri, cosendo ou fazendo renda; ou então deitada na rede, os cabelos soltos, a negra catando-lhe piolho, dando-lhe cafuné. (340-341)

En un libro repleto de alusiones a las relaciones entre los "señores del ingenio" y las esclavas, en una escena de encuentro interracial entre la "señorita" y la mucama, la energía erótica circula mucho más intensamente. Como sucede en el ejemplo de lo sucedido entre los jóvenes blancos y negros, Freyre trata sugerentemente una escena y luego continúa, esta vez para describir las asperezas de las "señoras del ingenio", casadas a los quince años de edad y dedicadas a la procreación hasta la destrucción completa de sus cuerpos. Vale recordar, para quien observa los debates sobre Freyre, tal vez perdiendo un poco de vista el texto de Freyre, que pocos relatos del periodo son más explícitos en lo que se refiere a las atrocidades de la esclavitud, sean estas los golpes de látigo, el estupro, el tráfico de seres humanos, los viajes degradantes de los negros, la supresión de prácticas religiosas, el trabajo forzado, el infanticidio, la discriminación y el fenómeno real y simbólico de lo que llamamos racismo. De la misma manera, las atrocidades vividas por las mujeres blancas - la tiranía del padre que es sustituida por la tiranía del marido, una vida entera dedicada a la procreación, la sustitución institucional del padre confesor por el médico - son procesos que Freyre describe en detalle. Es ne- 
cesario un acto de olvido brutal y una lectura selectiva para decir que Freyre "esconde" los horrores de la vida en las plantaciones de caña de azúcar. Pero esto no implica, como veremos a continuación, que no haya lugar en el texto para operaciones de silenciamiento.

Si la primera escena, decible, es el encuentro heterosexual que funda la nación - acompañada de su doble homoerótica, constitutivamente reprimida-, ¿cuál es la segunda escena sexual a la que se alude arriba? Si la escena visible, decible, que constituyó al país es el encuentro violento entre el "señor del ingenio" y las mujeres negras y mestizas, la escena indecible es la imagen obliterada y prohibida del hombre negro con la mujer blanca. He ahí una imagen mucho más perturbadora en la arquitectura de Casa-grande e senzala, que Freyre ataca con mucha más rapidez. Después de reconocer que hubo "casos de irregularidades sexuales entre señoras y esclavos" (338), clausura el asunto:

Nem as tradições nem os relatos dos estrangeiros merecedores de fé, nem as críticas, muitas vezes libelos, dos más-línguas desabusados da marca do padre Lopes Gama, autorizam-nos a concluir com M. Bonfim, no seu América Latina, "não raro a sinhá-moça criada a roçar os mulecotes, entrega-se a eles, quando os nervos degenerados acordam em desejos irreprimíveis; então intervém a moral paterna: castra-se com uma faca mal-afiada o negro ou mulato, salga-se a ferida, enterram-no vivo depois. A rapariga, com um dote reforçado, casa com um primo pobre [...] (338-339)

Esta es una de las pocas alusiones a esa imagen mucho más perturbadora para Casa-grande e senzala, que es el quiebre momentáneo del orden patriarcal a través de la transgresión racial de la mujer blanca con el hombre negro. Freyre exorciza la escena al decir que

o ambiente em que eram criadas nas casas-grandes dificilmente permitiria aventuras tão arriscadas [...] durante o dia, a moça ou menina branca estava sempre sob as vistas de pessoa mais velha ou de mucama de confiança. Vigilância que se aguçava durante a noite". (339)

Aquí, Freyre no simplemente supone saber, basado en testimonios, lo que sucedía en la casa-grande, en ese espacio fluido y permeable entre lo público y lo privado que era propio de la colonización brasileña; él también supone saber lo que no sucedía en aquel espacio sin testimonios, en los confines de lo privado. En otras circunstancias, Freyre sopesaría de forma diferente el testimonio de alguien como Manoel Bomfim, quien como él es un nombre 
clave en el desmontaje del racismo pseudocientífico en Brasil, a pesar de su posición mucho más materialista y progresista. Al clausurar la posibilidad planteada por Bomfim con la alusión a un supuesto poder casi perfecto del aparato represivo, Freyre, como en un desliz freudiano, siente la necesidad de recordarle al lector que "não louvamos o sistema: apenas procuramos lembrar sua quase incompatibilidade com aventuras da espécie referida por M. Bomfim" (340). Se trata de una suposición no usada comúnmente por Freyre en otros temas, que es evocada aquí con bases empíricas bastante frágiles. Es el equivalente a un aviso para un buen entendedor: ¿ cómo se atreve, lector, a sospechar que es de mi interés volver absolutos e insuperables los obstáculos que separan a los hombres negros de las mujeres blancas?

Con todo, la escena jamás es definitivamente exorcizada en la trilogía de Freyre. Sigue siendo inquietante, aun si se la expurga de las notas de pie de página, que en Casa-grande e senzala son, por sí mismas, una masiva biblioteca nacional. En el mismo momento en que Freyre descarta el relato de Bonfim sobre la castración de negros que transgredían la prohibición del contacto con mujeres blancas, añade un comentario: "[e]m Sabará, Minas Gerais, mostraram-nos no fundo do quintal de uma velha casa-grande dos tempos coloniais o lugar em que teria sido supliciado um escravo por ter sido surpreendido em relações com uma moça branca da casa" (401). Como comentario al propio texto donde lanza dudas sobre una aseveración de otro pensador, Freyre ofrece indicios que desmienten su propia tachadura de la escena. Esa tachadura, proponemos, está en el corazón y en el inconsciente de Casa-grande e senzala. El estatuto ambiguo del hombre negro en la narrativa de Freyre se torna aún más vívido cuando recordamos que, de los cinco capítulos del libro, los dos dedicados al negro son precisamente aquellos que llevan la palabra "sexual" en el título: "[o] escravo negro na vida sexual e de família do brasileiro" (429). Los capítulos dedicados al portugués y al indígena no llevan en sus títulos ninguna alusión al sexo. Este dato es curioso porque, según el propio Freyre, era el señor de esclavos de quien su "corpo quase se tornou exclusivamente o membrum virile" (429), mas es en los títulos dedicados al esclavo en que hace alusión al sexo. La paradoja no es gratuita y está en la base de la comprensión freyreana de Brasil. Se podría decir incluso que está en el corazón de la masculinidad nacional hegemónica, por más metamorfoseada que haya terminado siendo.

La explicación de Freyre para el acrecentamiento de la libido del señor de esclavos se encuentra en el terreno histórico-cultural, a saber, en la atmósfera de la casa-grande, con su entorno indolente, la ausencia de tareas 
para el macho que se encuentra al mando, la abundancia de mujeres esclavas, mestizas y blancas y, al fin, también la propia herencia mestiza traída por el colonizador. De ahí que Freyre utilice el término poligamia en dos sentidos diferentes, como resalta Ricardo Bezaquem de Araújo. En un primer sentido, estrictamente sociológico, designa las estructuras familiares propias de las sociedades amerindias. En otro, se trata de un "padrão muito menos rigoroso, definindo-se pela capacidade de sempre agregar um número cada vez maior de mulheres [...] no inconstante círculo que se reunia em torno do senhor" (66). Para Freyre, ese ambiente conducía a una especie de patriarcado bajo el principio de placer que se extendía, en el caso de los muchachos blancos y también mestizos, hasta el traumático momento en que eran arrancados de la casa-grande y eran llevados a la educación jesuita, pesadilla que Freyre narra en detalle en Sobrados e mucambos.

Cuando la cuestión de género en Freyre es leída atentamente, en toda su complejidad, nos encontramos entonces con una imagen un poco diferente de la ya gastada oscilación entre el endulzamiento de la atrocidad colonial y la celebración del mestizaje. Al observar cómo Freyre codifica las fuerzas hétero y homoeróticas de los hombres y mujeres, sean esclavos, mestizos o señores, encontramos algunos datos interesantes. A pesar de que Freyre hace algunas concesiones al lenguaje homofóbico con términos como pederastia (418) y al aludir a los crímenes de sodomía en la era colonial, la patologización y criminalización de la homosexualidad, propia del fin del siglo XIX y comienzos del XX, dejan al lenguaje de Freyre relativamente intacto. La retórica médico-positivista de "inversión" y "desvío" no están presentes. Este dato es importante porque esa tradición tuvo un impacto considerable en Brasil: criminólogos, antropólogos, psiquiatras y otros profesionales peroraron extensamente sobre la homosexualidad como patología o crimen. La versión freyreana canónica de Brasil, por otro lado, sugería que "a cultura se teria enriquecido e a atividade diferenciado entre os primitivos por efeito da homo ou da bissexualidade" y que "teriam os homo e os bissexuais desempenhado valiosa função criadora, lançando as bases de ciências, artes e religões. Teriam sido os profetas, os videntes, os curandeiros, os médicos, os sacerdotes, os artistas plásticos" (Casa-grande 118). El mundo descrito por Freyre es decididamente heteronormativo, no hay duda. Aunque los impulsos, prácticas y sensibilidades gays se hacen presentes constantemente. Además de las menciones a la persecución colonial contra la homosexualidad, hechas por Freyre en un lenguaje relativamente neutro, otras referencias a gays en Casa-grande e senzala siguen el mismo patrón. Un ejemplo es la alusión a los Bororos, 
en cuya sociedad, según Freyre, vivían "os mancebos em livre intercurso sexual uns com os outros; isto sem ar de pecado, mas naturalmente" (118). Las descripciones del ritmo lento, erotizado e indolente de la vida alrededor de la casa-grande conducen, para Freyre, a una libido exacerbada, que sería la característica del sistema colonial portugués. Tal libido es codificada como heterosexual, pero el libro nunca termina de establecer completamente una separación clara. Hay siempre en Freyre una frontera fluida entre la hétero y la homosexualidad. ${ }^{4}$

Las intersecciones entre raza y género en Casa-grande e senzala incluyen también interesantes superposiciones entre ellas, en la medida en que hay una serie de asociaciones entre, por ejemplo, la negritud (o mulatez) y lo femenino. A lo largo de la obra, se atribuyen a los afrodescendientes características femeninas en aquella que es tal vez la más grande operación ideológica de Casa-grande e senzala, más poderosa, a mi parecer, que el mito de la "democracia racial". Lo que se testimonia en Freyre no es, sin embargo, la infantilización o la feminización propia de la antropología colonialista, según la cual los pueblos colonizados eran presentados como más atrasados o frágiles. Sin duda, ese no es el sentido en que en la obra de Freyre aparece el reconocimiento de la identidad, como se puede ver en la abundante selección de atributos que serían comunes a lo femenino y a lo mulato: maleabilidad, adaptabilidad, dulzura, etc. En este escenario paradojal, el orden patriarcal es atravesado por una lógica femenina, en un contexto en el que, recordemos, el "ingenio" era frecuentemente marcado por la ausencia del padre y el liderazgo de la madre, tema constante en la obra de Freyre. Esta lógica coexiste paradójicamente con el supuesto exceso de libido del "señor del ingenio" y funciona, simultáneamente, como instrumento de tachadura, borradura, de la masculinidad negra.

En Casa-grande e senzala, el sujeto masculino negro es objeto de una tachadura según la cual la feminización opera como indicador de desexualización. Es preciso desexualizar al negro. Tómese por ejemplo el análisis que hace Freyre sobre la función afrodisíaca de las danzas y rituales de ellos: según Freyre, esas ceremonias no indicarían un exceso de "lubricidad", sino su ausencia, en una lógica según la cual los afro-brasileños necesitarían

4 Esa fluidez en los límites entre homo y heterosexualidad aparece en las propias referencias autobiográficas de Freyre. Para un análisis de la dinámica interracial y jerarquizada de las relaciones homosexuales masculinas en Casa-grande e senzala, véase el trabajo de César Braga Pinto publicado en este mismo dossier. 
elementos externos para accionar la libido. En el tema de la sexualidad del hombre negro, Freyre manipula un cuchillo de doble filo que, por un lado, cuestiona el mito del negro animalizado y salvaje pero, por otro, claramente intenta exorcizar el fantasma de la sexualidad negra transgresora. Esa curiosa ecuación entre lo femenino y lo asexuado se sustenta sobre el hecho de que, en el retrato freyreano del Brasil colonial, la sexualidad es asociada a la energía viril del "señor del ingenio", en un escenario que se presupone heterosexual pero que está velado, como vimos, por impulsos gays. Por otro lado, la sexualidad del hombre negro es objeto de una preocupada negación de Freyre en el momento en que su texto se abre a la consideración de rumores y testimonios acerca de los encuentros de negros con blancas. Paralelamente a esas dos operaciones, el texto de Freyre hace reiteradas asociaciones entre el mulato y la suavidad femenina: "Molície - certas ternuras de moça, certos modos doces, gestos quase de mulher agradando homem, em torno do branco socialmente dominante" (Sobrados 647). En oposición a "suavidad" (moleza), la palabra escogida por Freyre "molície" (delicadeza) también era el término usado por la Inquisición para designar prácticas sexuales sin penetración. ${ }^{5}$ Al feminizar a los afrodescendientes, Freyre sin duda intentaba exorcizar la amenaza del hombre negro viril en Casa-grande e senzala, pero el cuadro se complicaría un poco en la continuación de la trilogía, Sobrados e mucambos.

En el libro de 1936, junto con la prevista referencia a un aura "más caliente" de la mulata, encontramos alusiones a los "boatos sobre vantagens de ordem física que fariam dele [mulato] ou do negro o superior do branco puro e louro no ato do amor" (1324). En esta ocasión, Freyre va mucho más allá en el tema del negro con la blanca, en pasajes que recuerdan inclusive a las Mil y una noches, donde ya hay referencias a la atracción sentida por "mujeres finas" hacia "hombres de razas más oscuras". Una de las explicaciones de Freyre para los casamientos endógenos, entre primos, en Pernambuco, San Pablo y Bahía, así como para la gran cantidad de mujeres enviadas a conventos en Minas Gerais, es el hecho de que los patriarcas querían evitar "o embaraço de escolher genro entre os homens solteiros da terra, de branquidade porventura duvidosa" (916). En contraste con la imagen feminizada de los afro-brasileños ofrecida en Casa-grande e senzala, en la obra siguiente

5 Debo a la obra Erotismo à brasileira, de Helena Bocayuva, recuerdos acerca de varias referencias a la sexualidad en la obra de Freyre. Se trata de un libro útil sobre el tema que, ciertamente, habría ganado en relevancia si, en lugar de glosas y resúmenes de la obra de Freyre, hubiese ofrecido una lectura crítica más distanciada del autor. 
encontramos mención del "celo furioso o envidia sexual" de los hombres blancos en relación a los negros, en un notable reconocimiento de que "para contrariar o encanto do macho negro sobre a mulher branca, o branco civilizado teria procurado desenvolver uma aura de ridículo e de grotesco em volta do preto" (1325). La atención a los miedos sexuales del blanco como un componente del racismo era, sin duda, un elemento nuevo allí, ausente en el libro anterior. Para el pensamiento social brasileño del momento, esa era una noción más perturbadora y revolucionara que la propia crítica de Freyre al biologismo, y había sido ignorada en las críticas al Freyre como promotor de una supuesta democracia racial. Es verdad que se trata de breves fragmentos sin mucho eco en el texto freyreano y por tanto no sorprende que no hayan sido explorados en la bibliografía secundaria. En la esfera del sexo interracial durante el periodo en que se focaliza el libro (el declive del orden patriarcal rural), los encuentros entre inmigrantes portugueses o italianos y brasileñas negras o mestizas fue, por cierto, un hecho histórico mucho más sancionado. Es esta la escena, menos perturbadora, que toma el centro del ensayo cuando Freyre pasa a la ascensión del mulato y al fenómeno del mestizaje en Sobrados e mucambos.

Al contrario de lo que reza la percepción común, es precisamente en el momento en el que el mestizaje es el tema en cuestión -o sea, en las últimas secciones de Sobrados e mucambos - que las denuncias de Freyre al racismo se vuelven más directas y pronunciadas. Freyre se refiere al horror de los blancos frente a la posibilidad de una mayoría afro-brasileña en la época de la Independencia, relata la revuelta de los negros y mestizos en Recife en 1823, se ocupa de la hipótesis de Roger Bastide de que los negros libertos estarían intentando restaurar un concepto africano de familia ampliada como apoyo contra la discriminación, detalla la represión y la exclusión de los mestizos calificados en el mercado como un instrumento más en la mantención de la anacrónica institución de la esclavitud y, finalmente, discute hasta las distorsiones en las imágenes componentes en el proyecto de blanqueamiento del Brasil (Sobrados 1331-1344). El sexo interracial recibe otra referencia y, una vez más, las parejas negro-blanca son tratadas de forma bien distinta de las parejas blanco-negra. Citando a Johann Rugendas, el pintor alemán que viajó largamente por Brasil en el siglo XIX, Freyre nota que los casamientos entre hombres blancos y mujeres "de color" eran "comunes en las clases medias e inferiores" y también sucedían "algunas veces en las clases más elevadas". No hay mención a grandes obstáculos a esas relaciones. Por otro lado, "cuando una mujer blanca de una familia rica y respetada se desposaba 
con un hombre de color muy oscuro, había algún escándalo: aunque 'espanto' más que 'censura"' (1335).

Que Rugendas -y, por extensión, Freyre, que lo cita aprobatoriamente- tratase los dos casos de forma distinta está, es claro, justificado. Ellos eran y son diferentes. Lo que interesa aquí es la curiosa oscilación de vocablos, que de nuevo relativiza una violenta prohibición al echar mano del equilibrio de antagonismos. Después de admitir que una pareja negro-blanca era motivo de "algún" escándalo, Rugendas y Freyre descartan la posibilidad de "censura", rebajándolo a un mero "espanto". Es como si la referencia a la censura fuese necesaria precisamente para ser negada. Sobrados e mucambos ciertamente va más allá que Casa-grande e senzala en el tratamiento de esa intersección perturbadora entre raza y género en el campo de la sexualidad, pero nuevamente Freyre asume el papel de normalización y exorcización de la escena. En el mundo real, como sabemos, las cosas evolucionarían de forma un poco diferente. Como demuestra la investigación de Thales de Azevedo sobra las "élites de color", por ejemplo, aún en el siglo XX había una prohibición silenciosa, no dicha, que impedía que las blancas bailaran con negros, ya que eso podría ser motivo de "constreñimiento" para ellas, un bloqueo harto más estricto que cualquier obstáculo enfrentado por las parejas blanco-negra. Otros ejemplos de esta asimetría en las relaciones interraciales, semejantes a aquellas documentadas por Thales de Azevedo, podrían ser añadidas, tanto en el periodo imperial como en el republicano.

La obra de Freyre sería entonces, simultáneamente, testimonio, análisis y tachadura de esa asimetría, tanto en lo que la obra dice como en lo que silencia. El entrecruzamiento de lo dicho y lo no dicho en Casa-grande e senzala es, en efecto, un componente clave de lo que podríamos llamar el inconsciente de este libro. No es menor el mérito de esta obra porque ese inconsciente sea, en gran medida, el inconsciente de los relatos dominantes que el pensamiento brasileño ha contado sobre sí mismo. No se trata, en otras palabras, de valorar si el lenguaje de Freyre se adecúa a su referente, si describe correcta o incorrectamente una determinada realidad. Más importante que eso es observar cómo la obra de Freyre capta, replica, formula de manera definitiva el mecanismo retórico por excelencia con el cual los discursos hegemónicos - y hegemónicos aquí quiere decir, gramscianamente: "diseminados por todo el cuerpo social" - han representado esa realidad. Escaparse de un marco simplificado que fuerza el debate a una cansada oscilación entre reivindicar a Freyre y condenar a Freyre bien puede ser, hoy, la vereda más 
productiva para adentrarse en ese inconsciente y comprender los funcionamientos de ese poderoso mecanismo retórico.

\section{Obras citadas}

Amado, Gilbert, et al. Gilberto Freyre: Sua ciência, sua filosofia, sua arte. Río de Janeiro: José Olympio, 1962. Impreso.

Arroyo, Jossianna. "Brazilian Homoerotics: Cultural Subjectivity and Representation in the Fiction of Gilberto Freyre". Lusosex: Gender and Sexuality in the Portuguese-Speaking World. Ed. Susan Canty Quinlan and Fernando Arenas. Minneapolis y Londres: Universidad de Minnesota, 2002. 57-83. Impreso.

Azevedo, Thales de. As elites de cor: Um estudo de ascensão social. São Paulo: Editora Nacional, 1955. Impreso.

Benzaquen de Araújo, Ricardo. Guerra e paz: Casa-grande e senzala e a obra de Gilberto Freyre nos anos 30. Río de Janeiro: Editora 34, 1994. Impreso.

Bocayuva, Helena. Erotismo à brasileira: O excesso sexual na obra de Gilberto Freyre. Río de Janeiro: Garamond, 2001. Impreso.

Braga-Pinto, César. "The Sugar Daddy: Gilberto Freyre and the White Man's Love for Blacks". The Masters and the Slaves: Plantation Relations and Mestizaje in American Imaginaries. Ed. Alexandra Isfahani-Hammond. Nueva York: Palgrave, 2005. 19-33. Impreso.

Costa Lima, Luiz. "A versão solar do patriarcalismo: Casa grande e senzala". Aguarrás do tempo. Río de Janeiro: Rocco, 1989. 187-238. Impreso.

De Castro Rocha, João Cezar. "Notas para uma futura pesquisa: Gilberto Freyre e a escola paulista". O imperador das idéias. Gilberto Freyre em questão. Orgs. Joaquim Falcao y Rosa María Barbosa Araújo. Río de Janeiro: Topbooks, 2001. 183-203. Impreso.

Dunn, Christopher. "A retomada freyreana". Gilberto Freyre e os estudos latinoamericanos. Orgs. Joshua Lund y Malcolm McNee. Pittsburgh: Instituto Internacional de Literatura Iberoamericana, 2006. 35-51. Impreso.

Falcão, Joaquim. "A luta pelo trono: Gilberto Freyre versus USP". O imperador das ideias: Gilberto Freyre em questão. Orgs. Joaquim Falcão y Rosa Maria Barboza de Araújo. Río de Janeiro: Topbooks, 2001. 131-167. Impreso.

Fonseca, Edson Nery de, org. Casa-grande e senzala e a crítica brasileira de 1933 a 1944. Recife: Companhia Editora de Pernambuco, 1985. Impreso.

Freyre, Gilberto. Casa-grande e senzala. 1933. Vigésima edición. Río de Janeiro y Brasilia: José Olympio - INL-MEC, 1980. Impreso.

Freyre, Gilberto. "Maternalismo na formação brasileira". Diário de Pernambuco. 24 de diciembre de 1950. Web. 17 de febrero de 2012. 
Freyre, Gilberto. New World in the Tropics: The Culture of

Modern Brazil. Nova York: Knopf, 1959. Impreso.

Freyre, Gilberto. Ordem e progresso. Intérpretes do Brasil. 1957, Vol. 3. Org.

Silviano Santiago. Río de Janeiro: Nova Aguilar, 2000. 7-898. Impreso.

Freyre, Gilberto. Sobrados e mucambos. Intérpretes do Brasil. 1936, Vol. 2. Org.

Silviano Santiago. Río de Janeiro: Nova Aguilar, 2000. 729-1461. Impreso.

Giucci, Guillermo y Enrique Rodríguez Larreta. "Casa-Grande e Senzala:

História da recepção". Casa-grande e Senzala. Por Gilberto Freyre. Coords.

Guillermo Giucci, Enrique Rodríguez Larreta y Edson Nery da Fonseca.

Barcelona - La Habana - Lisboa - París - México - Buenos Aires - San Pablo

- Lima - Guatemala - San José: ALLCA XX, 2002. 927-952. Impreso.

Guimarães, Antonio S. Alfredo. Classes, raça e democracia. 2a

edição. Río de Janeiro: Editora 34, 2002. Impreso.

Guimarães, Antonio S. Alfredo. "Racial democracy”. Manuscrito inédito. Web. 17 de

febrero de 2012. http://www.fflch.usp.br/sociologia/asag/Racial\%democracy.pdf

Laferrièrre, Dany. Comment faire l'amour avec un nègre sans se fatiguer. Montreal: Vlb Éditeur, 1985. Impreso.

Lund, Joshua y Malcolm McNee, orgs. Gilberto Freyre e os estudos latino-americanos.

Pittsburgh: Instituto Internacional de Literatura Iberoamericana, 2006. Impreso.

Maybury-Lewis, David. The Masters and the Slaves de Gilberto Freyre. Trad.

Samuel Putman. Los Ángeles: Universidad de California P, 1987. Impreso.

Melo, Alfredo César. "Os mundos misturados de Gilberto Freyre".

Luso-Brazilian Review 43.2 (2006): 27-44. Impreso.

Mota, Carlos Guilherme. "A universidade brasileira e o pensamento de Gilberto

Freyre". O imperador das idéias. Gilberto Freyre em questão. Orgs. Joaquim Falcao

y Rosa María Barbosa Araújo. Río de Janeiro: Topbooks, 2001. 168-182. Impreso.

Mota, Carlos Guilherme. Ideologia da cultura brasileira (1933-

1974). Tercera edición. San Pablo: Ática, 1977. Impreso.

Pontes, Heloísa. "Entrevista com Antonio Candido". Revista

Brasileira de Ciências Sociais 16.47 (2001): 5-30. Impreso.

Quinlan, Susan y Fernando Arenas, eds. Luso-Sex: Gender and

Sexuality in the Portuguese-speaking world. Minneapolis and

Londres: Universidad de Minnesota P., 2002. Impreso.

Schwartz, Stuart B. Sugar Plantations in the Formation of Brazilian Society:

Bahia, 1550-1835. Cambridge: Cambridge UP, 1985. Impreso.

Vainfas, Ronaldo. "Sexualidade e cultura em Casa-grande \& senzala".

Casa-grande e Senzala. Por Gilberto Freyre. Coords. Guillermo Giucci,

Enrique Rodríguez Larreta y Edson Nery da Fonseca. Barcelona - La 
Habana - Lisboa - París - México - Buenos Aires - San Pablo - Lima

- Guatemala - San José: ALLCA XX, 2002. 711-785. Impreso.

Vianna, Hermano. "A meta mitológica da democracia racial". O imperador das idéias. Gilberto Freyre em questão. Orgs. Joaquim Falcao y Rosa María Barbosa Araújo. Río de Janeiro: Topbooks, 2001. 215-221. Impreso.

Viveros, Mara Vigoya. "Contemporary Latin American perspectives on masculinity". Changing Men and Masculinities in Latin America. Ed. Matthew Gutmann. Durham: Duke UP, 2003. 21-57. Impreso. 